\title{
Deteksi Dini Penyakit Arteri Perifer pada Pasien Diabetes Melitus di Kota Mataram
}

\author{
Yanna Indrayana $^{1}$, Herpan Syafii Harahap*2, Ilsa Hunaifi ${ }^{2}$ \\ ${ }^{1}$ Departemen Kadiologi, Fakultas Kedokteran Universitas Mataram, Mataram, Indonesia \\ ${ }^{2}$ Departemen Neurologi, Fakultas Kedokteran Universitas Mataram, Mataram, Indonesia
}

Article history

Received: 24-10-2020

Revised: 15-11-2020

Accepted: 24-11-2020

*Corresponding Author:

Herpan Syafii Harahap,

Fakultas Kedokteran

Universitas Mataram, Mataram

Nusa Tenggara Barat,

Indonesia

Email:

herpanharahap@unram.ac.id
Abstract: Diabetes mellitus is currently becoming a major public health problem in the world. The prevalence of diabetes mellitus globally in 2019 is estimated at $9.3 \%$ and will increase to $10.9 \%$ in 2040 . Peripheral artery disease is one of the important complications of diabetes mellitus. Patients with diabetes mellitus accompanied by peripheral artery disease have high morbidity and. Therefore, early detection of peripheral artery disease in diabetic patients is important. This event is carried out with the aim of early detection of peripheral artery disease in diabetes mellitus sufferers in Mataram. A total of 183 diabetes mellitus patients at the Siti Hajar Hospital, Mataram, were participated in this event, with an average age of 57 years and $67.8 \%$ of them were women. Most of the patients $(75.4 \%)$ had poor blood glucose control. Of these, $26.8 \%$ of patients had peripheral artery disease. Patients and/or caregivers showed high enthusiasm during the education regarding the detection results of the peripheral artery disease. This event was very useful in increasing the knowledge of diabetic patients, especially in terms of blood sugar control, prevention, and management of peripheral artery disease.

Keywords: atherosclerosis; complication; diabetes; mortality; patients

Abtrak: Diabetes melitus saat ini menjadi masalah kesehatan masyarakat utama di dunia. Prevalensi penyakit diabetes melitus secara global pada tahun 2019 diperkirakan sebesar 9,3\% dan akan meningkat menjadi 10,9\% pada tahun 2040 . Penyakit arteri perifer merupakan salah satu komplikasi penting dari diabetes melitus. Pasien diabetes melitus yang disertai dengan penyakit arteri perifer memiliki morbiditas dan mortlitas yang tinggi. Oleh karena itu, deteksi dini penyakit arteri perifer pada pasien diabetes melitus penting untuk dilakukan. Kegiatan pengabdian kepada masyarakat ini dilaksanakan dengan tujuan untuk mendeteksi dini penyakit arteri perifer pada penderita diabetes melitus di Kota Mataram. Sebanyak 183 pasien diabetes melitus di poliklinik RSI Siti Hajar Mataram berpartisipasi dalam kegiatan ini, dengan rerata usia 57 tahun dan $67.8 \%$ diantaranya adalah perempuan. Sebagian besar pasien $(75.4 \%)$ memiliki kontrol glukosa darah yang buruk. Dari jumlah tersebut, 26,8\% pasien mengalami penyakit arteri perifer. Pasien dan/atau keluarga yang mengasuh pasien menunjukkan antusiasme yang tinggi sewaktu dilakukan edukasi terkait hasil deteksi penyakit arteri perifer tersebut. Kegiatan pengabdian ini sangat bermanfaat dalam meningkatkan pengetahuan pasien-pasien diabetes melitus, terutama dalam hal kontrol gula darah, pencegahan, dan tatalaksana terhadap penyakit arteri perifer.

Kata Kunci: aterosklerosis; diabetes; kematian; komplikasi; pasen 


\section{PENDAHULUAN}

Diabetes melitus saat ini berkembang menjadi masalah kesehatan utama di dunia. Prevalensi penyakit diabetes melitus secara global pada tahun 2019 diperkirakan sebesar 9,3\% dan diperkirakan akan meningkat menjadi 10,2\% pada tahun 2030 dan 10,9\% pada tahun 2040 (Saeedi et al., 2019). Hasil Riset Kesehatan Dasar (Riskesdas) tahun 2018 menunjukkan bahwa prevalensi diabetes melitus di Indonesia mengalami kenaikan sebesar 1,6\% dari riset yang sama yang dilakukan pada tahun 2013 (Kementerian Kesehatan RI, 2018). Peningkatan prevalensi diabetes melitus tersebut terutama disebabkan karena peningkatan jumlah populasi usia lanjut, perkembangan ekonomi, urbanisasi, kebiasaan makan tidak sehat dan aktivitas banyak duduk. Saat ini populasi di Asia merupakan populasi utama yang mengalami epidemi diabetes melitus tipe 2 paling cepat (Zheng et al., 2018).

Prevalensi diabetes melitus memiliki hubungan erat dengan kejadian penyakit jantung dan pembuluh darah. Penyakit diabetes melitus merupakan salah satu faktor risiko penting untuk terjadinya penyakit jantung dan pembuluh darah dan juga merupakan salah satu penyebab utama tingginya mortalitas penyakit tersebut. Pasien dengan diabetes memiliki risiko 1,7 kali lebih tinggi untuk mengalami penyakit jantung dan pembuluh darah dibandingkan dengan pasien tanpa diabetes melitus, baik pada kelompok laki-laki maupun perempuan (Leon dan Maddox, 2015).

Penyakit jantung dan pembuluh darah pada pasien dengan diabetes melitus dapat didapatkan dalam bentuk penyakit jantung koroner, stroke, penyakit arteri perifer dan gagal jantung. Patologi yang mendasari terjadinya penyakit-penyakit tersebut adalah berkembangnya aterosklerosis pada pembuluh darah di jantung, otak, dan ekstremitas (Takahara et al., 2019). Penyakit arteri perifer merupakan salah satu bentuk penyakit jantung pembuluh darah yang banyak ditemukan dan 20-30\% penderitanya memiliki penyakit diabetes melitus (Thiruvoipati et al., 2015). Disamping itu, diabetes melitus juga meningkatkan morbiditas dan mortalitas akibat penyakit arteri perifer Vrsalovic et al., 2017). Untuk menekan morbiditas dan mortalitas penyakit arteri perifer pada pasien diabetes tersebut diperlukan langkah-langkah pencegahan dan deteksi dini. Selain kontrol kadar gula darah yang baik, strategi lain yang dapat dilakukan yaitu deteksi dini proses ateroklerosis dengan pemeriksaan Ankle Brachial Index (ABI).

Ankle Brachial Index (ABI) yaitu pemeriksaan non-invasif sederhana yang dapat digunakan untuk mendeteksi terjadinya aterosklerosis. ABI dihitung dengan membandingkan rasio tekanan darah sistolik tungkai yang tertinggi dengan tekanan darah sistolik lengan tertinggi. Ankle Brachial Index (ABI) dengan skor $\leq 0.9$ dan $>1.4$ dikategorikan abnormal dan memiliki risiko tinggi untuk mengalami penyakit arteri perifer. ABI yang rendah $(\leq 0.9)$ baik dengan atau tanpa gejala sangat berhubungan dengan kejadian aterosklerosis sistemik dan peningkatan kematian akibat kardiovaskular, termasuk penyakit arteri perifer (Miura et al., 2017).

Pasien dengan penyakit arteri perifer (skor $\mathrm{ABI} \leq 0.9$ ) yang memiliki komorbid diabetes melitus memiliki risiko lebih tinggi untuk mengalami kematian dibandingkan dengan pasien dengan penyakit arteri perifer yang tidak memiliki komorbid diabetes melitus (Alvares-Cabratosa et al., 2019). Dengan demikian penentuan skor ABI pada pasien dengan diabetes melitus sebagai upaya untuk deteksi dini proses aterosklerosis sistemik yang nantinya akan mempengaruhi manajemen pengobatan dan prognosis dari pasien merupakan upaya penting yang harus dilakukan. Deteksi dini penyakit arteri perifer pada penderita diabetes melitus tersebut belum pernah dikerjakan di Kota Mataram. Berdasarkan paparan diatas, kegiatan pengabdian kepada masyarakat ini dilaksanakan 
dengan tujuan untuk mendeteksi dini penyakit arteri perifer pada penderita diabetes melitus di Kota Mataram.

\section{METODE}

Kegiatan pengabdian kepada masyarakat ini dilaksanakan di Poliklinik Rumah Sakit Islam (RSI) Siti Hajar Mataram selama Bulan Juni-Oktober 2010. Jumlah pasien diabetes melitus yang ditargetkan untuk berpartisipasi dalam kegiatan pengabdian kepada masyarakat ini sebanyak 200 orang. Setiap pasien yang diketahui menderita diabetes melitus yang datang ke poliklinik diberikan informasi mengenai pemeriksaan Ankle Brachial index (ABI) dan diminta datang pada tanggal dan waktu yang telah ditentukan (nama dan nomor telepon pasien dicatat untuk dihubungi pada saat 1 hari sebelum pemeriksaan). Pemeriksaan ABI dilakukan apabila dalam sehari terdapat minimal 10 pasien diabetes melitus yang bersedia untuk dilakukan pemeriksaan ABI. Data mengenai diagnosis penyakit pasien diperoleh dari wawancara, hasil pemeriksaan laboratorium, dan riwayat pengobatan sebelumnya yang terdapat di rekam medis pasien.

Pada saat hari pemeriksaan, dilakukan pengambilan data mengenai karakteristik demografik dan klinik pasien, meliputi usia, jenis kelamin, riwayat penyakit diabetes melitus (terkontrol atau tidaknya penyakit diabetes melitus dan jenis pengobatannya), dan riwayat hipertensi. Data-data tersebut diperlukan untuk menganalisis hasil pemeriksaan ABI dan edukasi kepada pasiennya terkait hasil analisis tersebut. Pada tahap berikutnya, dilakukan pemasangan manset tensimeter dan dipertahankan pada nilai tekanan darah sistolik tungkai tertinggi (antara arteri dorsalis pedis dan arteri tibialis posterior) dan tekanan darah sistolik lengan tertinggi (antara arteri brakialis lengan kanan dan kiri). Pada kondisi tersebut, dilakukan pemeriksaan dengan alat dopler vaskuler untuk menentukan tekanan darah secara akurat. Dari pemeriksaan tersebut diatas dapat ditentukan skor ABI pasien diabetes melitus.

Pada tahap akhir, masing-masing pasien diberikan informasi mengenai hasil pemeriksaan skor ABI dan data karakteristik demografik dan klinik yang dimilikinya. Berdasarkan data-data tersebut, pasien yang terdeteksi memiliki penyakit arteri perifer diberikan edukasi dan saran mengenai langkahlangkah selanjutnya yang harus dilakukan, meliputi pemeriksaan penunjang, pengobatan, dan modifikasi pola makan dan aktivitas fisik sehari-hari, untuk mencegah progresivitas penyakit kearah yang lebih berat. Untuk pasien yang tidak memiliki penyakit arteri perifer, diberikan edukasi dan saran mengenai modifikasi pola makan dan aktivitas fisik sehari-hari sebagai upaya preventif agar mereka tidak sampai menderita penyakit arteri perifer. Data-data mengenai skor ABI, karakteristik demografik dan klinik seluruh pasien yang berpartisipasi dalam kegiatan pengabdian kepada masyarakat ini akan disajukan dalam tabel distribusi frekuensi

\section{HASIL DAN PEMBAHASAN}

Dari 200 pasien diabetes melitus di poliklinik RSI Siti Hajar yang ditargetkan untuk mengikuti kegiatan pengabdian kepada masyarakat ini, sebanyak 183 pasien $(91,5 \%)$ yang berpartisipasi penuh dalam kegiatan tersebut. Sebanyak 17 pasien $(8,5 \%)$ tidak hadir dalam pelaksanaan kegiatan yang telah dijadwalkan dikarenakan beberapa alasan, antara lain tidak ada yang mengantar, jarak antara tempat tinggal dan rumah sakit yang relatif jauh, dan menganggap kegiatan tersebut tidak diperlukan. Keikutsertaan pasien yang mencapai $91,5 \%$ dari total peserta yang ditargetkan tersebut menunjukkan 
tingginya antusiasme dan tingkat partisipasi dari pasien diabetes melitus tersebut. Hal ini menunjukkan tingkat kesadaran pasien diabetes melitus terhadap pentingnya identifikasi penyakit arteri perifer sebagai komplikasi penting penyakit diabetes melitus yang dideritanya tersebutb sangat tinggi.

Rerata usia peserta kegiatan pengabdian kepada masyarakat ini adalah 57 tahun. Sebagian besar pasien berjenis kelamin perempuan dan memiliki riwayat penyakit hipertensi. Sebagian besar pasien memiliki kontrol yang kurang bagus terhadap penyakit diabetesnya, meskipun telah mendapatkan pengobatan, baik obat antidiabetik oral, insulin maupun kombinasi dari keduanya (Tabel 1). Hal ini menunjukkan bahwa tingkat pengetahuan pasien mengenai bagaimana cara mendapatkan kontrol gula darah yang baik dan apa saja komplikasi yang dapat terjadi akibat kontrol gula darah yang tidak bagus masih kurang. Pasien yang memiliki kontrol gula darah yang tidak bagus tersebut sebagian besar sudah merasa cukup dengan menggunakan obat-obat diabetes yang diterimanya, tanpa memperhatikan jumlah kalori makanan yang masuk, tanpa identifikasi sumber-sember makanan dengan nilai kalori yang tinggi, dan kurangnya monitor kadar gula darah secara mandiri. Menurut Haghighatpanah et al., (2018); dan Mamo et al., (2019). Permasalahan-permasalahan tersebut merupakan faktor penyebab kegagalan kontrol gula darah yang sangat umum terjadi
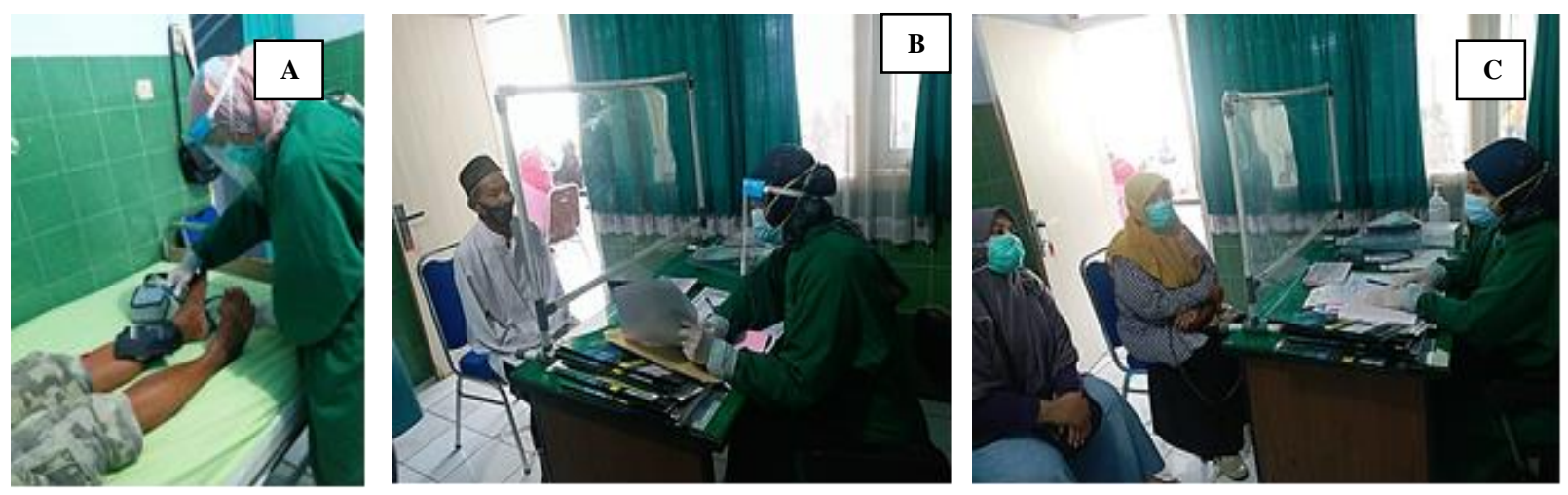

Gambar 1. Rangkaian kegiatan deteksi dini penyakit arteri perifer pada pasien diabetes melitus. A. Pemeriksaan tekanan darah dan dopler vaskuler untuk penentuan skor ABI. B. Edukasi kepada pasien diabetes melitus tanpa komplikasi penyakit arteri perifer. C. Edukasi kepada pasien diabetes melitus dengan komplikasi penyakit arteri perifer dan anggota keluarga yang mengasuhnya

Kegiatan ini bermanfaat sebagai media untuk memberikan edukasi yang memadai mengenai bagaimana cara mencapai kontrol gula darah yang baik tersebut. Edukasi yang bersifat personal, artinya diberikan melalui tatap muka langsung antara dokter dan pasien secara individual akan memberikan kesempatan bagi tiap-tiap pasien untuk mendapatkan penjelasan secara adekuat dan bertanya secara langsung untuk mengatasi kebingungan atau keraguan atas informasi yang diterimanya. Sewaktu bertatap muka secara langsung dengan dokter dalam suatu ruangan pemeriksaan yang menjaga privasi pasien, pasien menunjukkan antusiasme yang tinggi dan motivasi yang tinggi untuk bisa mendapatkan kontrol gula darah yang baik (Gambar 1).

Pada kegiatan ini, sebesar 26,8\% dari pasien diabetes melitus terdeteksi memiliki penyakit arteri perifer (Tabel 1). Prevalensi ini cukup tinggi dan sesuai laporan hasil studi epidemiologi penyakit arteri perifer sebelumnya yang berada dalam rentang 10-29\% (Dhaliwal and Mukherjee, 2007; Shu and Santulli, 2018). Tingginya angka prevalensi penyakit arteri perifer tersebut merupakan dampak 
dari kurang bagusnya kontrol gula darah pasien-pasien diabetes, seperti yang telah dipaparkan sebelumnya. Edukasi mengenai upaya-upaya yang harus dilakukan untuk menghambat progresivitas penyakit arteri perifer tersebut sangat penting untuk dilakukan. Pada kelompok pasien yang memiliki penyakit arteri perifer tersebut, edukasi tidak hanya diberikan kepada pasien, namun juga kepada anggota keluarga pasien yang sehari-hari turut merawat pasien (Gambar 1). Hal ini disebabkan karena keterlibatan anggota keluarga yang turut mengasuh pasien juga menjadi faktor penentu keberhasilan upaya pencegahan progresivitas penyakit arteri perifer pada pasien-pasien tersebut (Mendez et al., 2019).

Informasi yang harus diterima dengan baik oleh pasien dan anggota keluarga yang mengasuhnya adalah penyakit arteri perifer merupakan salah satu manifestasi aterosklerosis sistemik dan deteksi adanya penyakit arteri perifer pada pasien tersebut merupakan prediktor adanya risiko kejadian iskemik di kemudian hari. Dengan demikian, tindak lanjut terhadap hasil deteksi penyakit arteri perifer pada pasien tersebut sangat penting dalam upaya untuk mengurangi risiko kejadian kardiovaskuler akut, meminimalkan risiko disabilitas jangka panjang dan memperbaiki kualitas hidup pasiennya (Marso and Hiatt, 2006). Pada kelompok pasien diabetes yang memiliki penyakit arteri perifer tersebut, pasien dan anggota keluarga yang mendapinginya menunjukkan antusiasme yang tinggi dalam memperhatikan dan memahami informasi yang diberikan oleh dokter. Beberapa pasien diabetes yang memiliki penyakit arteri perifer dirujuk ke rumah sakit lain yang menjadi pusat rujukan yang lebih tinggi dan memiliki fasilitas penunjang yang lebih lengkap.

Tabel 1. Karakteristik pasien diabetes melitus

\begin{tabular}{llr}
\hline \multicolumn{1}{c}{ Kategori } & \multicolumn{1}{c}{ Sub-kategori } & Jumlah $(\mathbf{n}=\mathbf{1 8 3})$ \\
\hline Usia dalam tahun (rerata \pm SD) & & $57.27 \pm 9.86$ \\
Jenis kelamin, n(\%) & Laki-laki & $59(32.2)$ \\
& Perempuan & $124(67.8)$ \\
Hipertensi, $\mathrm{n}(\%)$ & Ya & $130(71.0)$ \\
& Tidak & $53(29.0)$ \\
Status diabetes melitus, n(\%) & Terkontrol & $45(24.6)$ \\
& Tidak terkontrol & $138(75.4)$ \\
Jenis pengobatan, $\mathrm{n}(\%)$ & Antidiabetik oral & $102(55.7)$ \\
& Insulin & $34(18.6)$ \\
Skor ABI (rerata \pm SD) & Kombinasi & $47(25.7)$ \\
Penyakit arteri perifer, $\mathrm{n}(\%)$ & & $0.99 \pm 0.16$ \\
& Ya & $49(26.8)$ \\
\hline SD=standard deviation; $\mathrm{ABI}=$ ankle brachial index & $134(73.2)$ \\
\hline
\end{tabular}

Melihat besarnya manfaat kegiatan pengabdian ini terhadap peningkatan status kesehatan pasien penyandang penyakit diabetes melitus, maka perlu diupayakan agar kegiatan ini dapat terus dilanjutkan. Kegiatan serupa juga perlu dilaksanakan di populasi dengan faktor risiko kardiovaskular lain seperti pasien hipertensi, perokok, obesitas, dislipidemia dan lain-lain. Perlu dilakukan monitor dan evaluasi dari hasil pemeriksaan Ankle Brachial Index ini terhadap perubahan tatalaksana pasien dengan diabetes melitus sehingga tujuan promotif dan preventif dari kegiatan ini dapat tercapai.

\section{KESIMPULAN DAN SARAN}


Hasil kegiatan deteksi dini penyakit arteri perifer dalam kegiatan pengabdian kepada masyarakat ini menunjukkan bahwa prevalensi penyakit arteri perifer pada populasi pasien diabetes melitus di Kota Mataram cukup tinggi. Kegiatan pengabdian kepada masyarakat ini sangat penting sebagai media memberikan edukasi secara adekuat kepada pasien-pasien diabetes melitus, terutama dalam hal kontrol gula darah yang baik, pencegahan, dan tatalaksana terhadap penyakit arteri perifer yang terdeteksi. Perlu dilakukan evaluasi tingkat keberhasilan upaya promotif dan preventif pada pasien diabetes melitus tanpa disertai komplikasi penyakit arteri perifer dan upaya kuratif dan rehabilitatif kepada mereka yang memiliki komplikasi penyakit arteri perifer dalam kurun waktu tertentu. Tingkat keberhasilan tersebut dapat dinilai dari stabilnya ABI dan rendahnya insidensi penyakit iskemik akut pada pasien diabetes melitus tersebut.

\section{Ucapan Terima Kasih}

Penulis mengucapkan terima kasih kepada Lembaga Penelitian dan Pengabdian kepada Masyarakat (LPPM) Universitas Mataram dan Rumah Sakit Islam (RSI) Siti Hajar Mataram yang telah membantu memfasilitasi terlaksananya kegiatan pengabdian ini.

\section{DAFTAR PUSTAKA}

Dhaliwal, G., and Mukherjee, D. 2007. Peripheral arterial disease: Epidemiology, natural history, diagnosis and treatment. International Journal of Angiology. vol 16 no 2, hal 36-44.

Haghighatpanah, M., Nejad, A. S. M., Haghighatpanah, M., Thunga, G., Mallayasamy, S. 2018. Factors that Correlate with Poor Glycemic Control in Type 2 Diabetes Mellitus Patients with Complications. Osong Public Health and Research Perspectives. vol 9 no 4, hal 167-174.

Kementerian Kesehatan RI. 2018. Hasil Utama Riskesdas 2018, https://www.kemkes.go.id/resources/download/info-terkini/hasil-riskesdas-2018.pdf, diakses tanggal 22 November 2020.

Leon, B. M., and Maddox, T. M. 2015. Diabetes and cardiovascular disease: Epidemiology, biological mechanisms, treatment recommendations and future research. World journal of diabetes. vol 6 , hal 1246.

Mamo, Y., Bekele, F., Nigussie, T., Zewudie, A. 2019. Determinants of poor glycemic control among adult patients with type 2 diabetes mellitus in Jimma University Medical Center, Jimma zone, south west Ethiopia: a case control study. BMC Endocrine Disorders. vol 19, hal 91.

Marso, S. P., and Hiatt, W. R. 2006. Peripheral arterial disease in patients with diabetes. Journal of the American College of Cardiology. vol 47 no 5, hal 921-929.

Mendez, C. B., Salum, N. C., Junkes, C., Amante, L. N., and Mendez, C. M. L. 2019. Mobile educational follow-up application for patients with peripheral arterial disease. Revista LatinoAmericana de Enfermagem. vol 27, hal e3122.

Miura, T., Minamisawa, M., Ueki, Y., Abe, N., Nishimura, H., Hashizume, et al. Impressive predictive value of ankle-brachial index for very long-term outcomes in patients with cardiovascular disease: IMPACT-ABI study. PloS one. vol 12 hal e0177609.

Saeedi, P., Petersohn, I., Salpea, P., Malanda, B., Karuranga, S., Unwin., N., et al. 2019. Global and regional diabetes prevalence estimates for 2019 and projections for 2030 and 2045: Results from the International Diabetes Federation Diabetes Atlas, 9th edition. Diabetes Research and Clinical Practice. vol 157, hal 107843.

Shu, J., and Santulli, G. 2018. Update on peripheral artery disease: Epidemiology and evidence-based facts. Atherosclerosis. vol 275, hal 379-381.

Takahara, M., Iida, O., Kohsaka, S., Soga, Y., Fujihara, M., Shinke, T. 2019. Diabetes mellitus and other cardiovascular risk factors in lower-extremity peripheral artery disease versus coronary artery disease: an analysis of 1,121,359 cases from the nationwide databases. Cardiovascular Diabetology. vol 18, hal 155. 
Thiruvoipati, T., Kielhorn, C. E., and Armstrong, E. J. 2015. Peripheral artery disease in patients with diabetes: Epidemiology, mechanisms, and outcomes. World Journal of Diabetes. vol 6, hal 961969.

Vrsalovic, M., Vucur, K., Presecki, A. V., Fabijanic, D., and Milosevic, M. 2017. Impact of diabetes on mortality in peripheral artery disease: a meta-analysis. Clinical; Cardiology. vol 40, hal $287-$ 291.

Zheng, Y., Ley, S. H., and Hu, F. B. 2018. Global aetiology and epidemiology of type 2 diabetes mellitus and its complications. Nature Reviews Endocrinology. vol 14, hal 88. 